\title{
Design of a Biomass Micro Gasifier Cookstove by CFD Modelling
}

\author{
Daham Liyanage, G.R.U. Senavirathna, Chamini Rodrigo, Pujitha Thennnakoon, \\ Pradeep Madawala and K.M. Muditha Dassanayake
}

\begin{abstract}
This paper presents computational fluid dynamic (CFD) analysis of a natural draft top-lit up-draft (TLUD) biomass cookstove which is acting as a micro pyrolyzing reactor to produce biochar. The effect of the top end geometry, the number of primary and secondary air inlets and their hole patterns, and the number of secondary air outlets and their hole patterns were considered in the design to optimize the performance. Seven different cookstove geometries were simulated to analyse the temperature and air distribution. ANSYS Fluent 16.0 was used to simulate the simplified 3D computational domains of the cookstove designs. The design with uniform air distribution and proper mixing of secondary air and the producer gas was selected as the best cookstove design to fabricate. Experiments were performed with the selected design and the results were compared with the predicted simulation results for evaluating the model. Results revealed a good correlation of $96.67 \%$ and a higher $R^{2}$ (coefficient of determination) value of 0.9344 for the temperature inside the combustion chamber. Thus, this modelling methodology can be used for the optimization of existing biomass cookstoves and for evaluating naval cookstove designs.
\end{abstract}

Keywords: Biomass, Cookstove, Natural draft, Top-lit up-draft, TLUD, CFD modelling

\section{Introduction}

Indoor air pollution cannot be neglected simply because people spend most of their time inside houses or buildings where the air is circulated in an enclosed environment. As per World Health Organization (WHO), in developing countries, the most vital indoor air pollutant is the combustion of unprocessed biomass fuels, for example, wood, agricultural residue and animal dung utilized for cooking [1]. The incomplete combustion of these solid fuels used in simple cooking stoves emits large amounts of respiratory particulate matter and toxic pollutants which release Carbon completely back to the atmosphere as Carbon Dioxide, which is a greenhouse gas contributing to global warming [2]. Exposure to these pollutants over a considerable time may result in developing cataracts, acute respiratory infections, heart diseases and pregnancy-related problems. Though the risk is high with the usage of biomass for cooking, many countries including Sri Lankan households use solid fuels for heating and cooking. According to the Global Health Observatory data repositories, in $2013,41 \%$ of the global population was using solid fuels which directly cause indoor air pollution and the majority were reported among lower and lower-middle income groups. When the populations consuming solid fuels that cause household air pollution were analysed in detail, the highest percentage was recorded as $79 \%$ from Africa and the next highest was 63\% who live in South-East Asia [3]. The majority of the population using solid fuels were recorded from rural areas compared to urban areas. The closest reasons for this could be the use of inefficient cookstoves which are cheaper and easy to use. Lack of awareness about the outcomes, lack of exposure to modern

Eng. Daham Liyanage, AMIE (Sri Lanka), B.Sc. Eng.

(Hons) (Ruhuna),

Email:dahamd.liyanage@gmail.com

(iD http://orcid.org/0000-0003-4893-0357

Eng. G.R.U. Senavirathna, AMIE (Sri Lanka), B.Sc. Eng. (Hons) (Ruhuna),

Email:grudayanga@gmail.com

(iD) http://orcid.org/0000-0001-5403-1193

Eng. Chamini Rodrigo, AMIE (Sri Lanka), B.Sc. Eng.

(Hons) (Ruhuna),

Email:chamini.rodrigo@gmail.com

(iD) $h$ ttp://orcid.org/0000-0001-8433-4136

Eng. Pujitha Thennnakoon, AMIE (Sri Lanka), B.Sc. Eng.

(Hons) (Ruhuna),

Email:pujithamthennakoon@gmail.com

(iD) http://orcid.org/0000-0003-4893-0357

Eng. Pradeep Madawala, AMIE (Sri Lanka)

B.Sc. Eng. (Hons) (Ruhuna),

Email:pradeepmadawala.ml@gmail.com

(iD) http://orcid.org/0000-0001-7799-2210

Eng. (Dr.) K.M. Muditha Dassanayake, B.Sc. Eng.

(Peradeniya), M Eng. (Tokyo, Japan), PhD (Tokyo, Japan),

CEng (UK), Senior Lecturer, Department of Mechanical and

Manufacturing Engineering, University of Ruhuna.

Email:mudithad@mme.ruh.ac.lk

(D) http://orcid.org/0000-0002-2400-3332 
technology and availability of raw materials for combustion can be some other reasons for the rural population to engage more in solid fuel combustion.

The most commonly used cooking device is the stove which comes in numerous designs, structures and configurations [4]. In ancient times, firewood was arranged in a pyramid shape and the cooking was done. This included many drawbacks as there is no control over fire which made fire hazards, produced smoke and resulted in low efficiency in cooking. So, the necessity of a form of shield fire arose, which ended up with the three-stone stove [5]. In the current context, cooking stoves have been evolved with numerous improvements and modifications according to the living country or region, purpose and the varying cooking tasks.

As in many countries, cooking stoves are highly used in the domestic sector of Sri Lanka. From the past to the present, the most commonly used traditional cookstove is the three-stone stove and semi-enclosed mud stove. Although many other improved versions of cooking stoves were designed with time the only popular stove was the two-pot "Aanagi-2" stove which controls the major drawbacks of open-fire up to some extent [6]. But all these stoves do not utilize a full burning process, which result in the emission of harmful gases and smoke and as most of the stoves use firewood as the fuel, it affects the environment directly. However, the use of these stoves have both short term and long term effects. But it is difficult to minimize or stop the usage as it is easy to use, economical and popular among the rural population.

Bio-char stove is an eco-friendly stove that came into the discussion as a solution for the typical stoves which consist of many shortcomings and harmful effects. Biochar is a solid material with enduring physical and chemical properties that could be used as a soil amendment to improve the fertility of the soil. It is obtained by the carbonization of biomass, which can be easily produced using biochar stoves [7]. The biochar production process is scientifically termed as "pyrolysis" which produces energy from biomass. In pyrolysis, the biomass is heated to moderate temperatures, in an environment where there is very little or no oxygen. This process differs from common ways of converting biomass into energy as the output of pyrolysis is a carbonrich porous solid by-product, biochar, which is stable to decay and an effective nutrient for plants as it can capture and lock carbon, nutrients and water into the soil [2]. With the temperature provided in the pyrolysis process, the produced biochar and its properties may differ. Biochar distinguishes from other charcoal fertilizers due to its high carbon capacity by being highly stable to decay and its ability to retain water and water containing nutrients. So, when biochar is added to soil, it enriches the fertility, which directly affects the plantations [2]. Other than being a soil amendment, biochar will mitigate climatic changes and reduce environmental pollution as well. Not merely as a soil amendment, the biochar can be used in various applications including medical, chemical and manufacturing fields due to its capability of retaining nutrients and the resistance to microbial decay [8].

Recently, modelling and simulation methods of the physical phenomenon have become useful for evaluating optimal operation parameters. These methods are important in the optimization of cookstove performance by saving time, money and energy. Based on the conservation of mass, momentum, energy and species, computational fluid dynamics (CFD) has been used to model the flow variations, thermal distribution and also to model the combustion of fuels and gasses in different cookstove designs. David et.al. [9] conducted CFD simulations for a production cookstove and developed a model for the steady, timeaveraged drying and pyrolysis of wood stick fuel. Simulation results were validated with the experimental results. Ravi et. al. [10] performed CFD simulations to describe the flow behaviour, heat transfer, pyrolysis and combustion of a sawdust stove configuration. These simulation results were used to develop a model to describe the performance of the cookstove and to make qualitative predictions. Later, this model was used to optimize the sawdust stove. Kalla et al. [11] developed a CFD model for a natural draft residential wood log stove to describe the chemical and physical phenomena. The model was able to describe the chemical process of wood log combustion, velocity profile, temperature distribution and chemical species concentrations inside the cookstove.

Different designs of biomass cookstoves were tested under different operating conditions for better performance. It is a commonly realized factor that adequate mixing of oxygen with the fuel is necessary for the complete combustion of 
fuel unless it results in increasing emissions going through an incomplete combustion process. It is observed that forced draft configuration increases the heat transfer to a cooking vessel and diminishes the amount of $\mathrm{CO}$ and particular matter which are results of incomplete combustion when compared with other available cookstoves [12]-[14]. Similar experiments were performed using natural draft, forced draft and with the combination of both conditions. Using varying secondary airflow and fixed primary airflow, the influence on the emissions during the combustion process was tested. Three phases were identified as lighting, steady-state and char. In the steady-state phase, emissions due to incomplete combustion were reduced by providing adequate secondary air which was achieved either by setting the secondary air inlet closer to the solid fuel stack or by forced secondary airflow [15]. In another study, experiments were performed using a top-lit-updraft (TLUD) cookstove by making variations in secondary airflow rate, secondary air inlet velocity and primary airflow rate. From this study also it was found that the $\mathrm{CO}$ emissions decrease when the secondary airflow increases [16]. Mukunda et al. [17] performed a study and found that the secondary air inlet hole diameter affects the performance of a stove. It was also suggested to have a larger secondary inlet hole diameter for better performance of a TLUD gasifier cookstove. With identifying the significance of mixing of air for the enhancement of efficiency and lessening the emissions, a wide number of cookstoves try to assist forced draft configuration. With the use of blowers or fans, the cost of a cookstove rises to a considerable level. In contrast, natural draft cookstoves are economical and easy to manufacture [18].

Gunawardena et al. [19] designed a TLUD biochar stove with an inner chamber in which secondary air hole inlets ran throughout the inner chamber. The stove generated heat from corn cob wastes to boil 1.5L of water in 20 minutes. On top of this design, Dassanayake et al. [20] performed experiments with a natural draft TLUD cookstove to analyse the performance using two combustion chamber design configurations. The cookstove with the most efficient combustion chamber was able to boil one litre of water to $100^{\circ} \mathrm{C}$ (at the atmospheric pressure) from burning corn cobs for 10 minutes and the average firing time was 17.32 minutes [20]. The yield of biochar by weight was $20 \%$.
Rodrigo et al. [21] developed a TLUD cookstove based on the results obtained from the research conducted by Dassanayake et al. [20]. The dimensions of this design were initiated based on anthropometric factors. It describes that the cookstove should be a tabletop domestic cookstove that can be easily handled by Sri Lankan housewives. Also, it considered the capability of producing a heat output needed to cook for an average of four people at a single burning process. A simulation model was developed for the design using ANSYS Fluent and obtained the temperature, velocity and air density contours. Experiments were conducted with the fabricated setup and the results were compared with the simulation results to validate the developed simulation model. A good correlation was achieved for the temperature values.

The firing time is a user parameter that depends on the mass of the fuel content added to the stove as no fuel is added halfway of the burning process and on the quality of airflow. As per the general sense, it nearly takes 30 minutes to cook rice for an average of four people on a normal three-stone stove. So, based on the experimental data obtained, the volume of the existing cookstove combustion chamber has to be altered by performing a dimension analysis to hold more content of raw materials. At the same time, airflow quality has to be optimized for an efficient combustion process.

This study presents the design improvements made for a small scale, eco-friendly and economical cookstove that generates energy from corn cobs or cinnamon sticks from natural draft air configuration. ANSYS FLUENT 16.0 was used as the computational modelling tool to simulate different design configurations. As the energy source, corn cobs or cinnamon sticks will be utilized as a substitute to the firewood, which is freely available in Sri Lanka as an agricultural waste without being utilized for any profitable aspect. The stove is designed with the top-lit up-draft (TLUD) technique which is easy to input raw materials, light up and take away the biochar produced after the process.

\section{Materials and Methods}

\subsection{New Design}

To establish TLUD stoves in the local community, the stove and its operations should go along with the user requirements. The performance of the stove can be evaluated by some factors from both designer's and user's 
Table 1 - Geometrical Parameters of the Cookstove Designs used in the Simulation

\begin{tabular}{ccccc}
\hline $\begin{array}{c}\text { Model } \\
\text { Number }\end{array}$ & $\begin{array}{c}\text { Deflector } \\
\text { type }\end{array}$ & $\begin{array}{c}\text { No. of primary } \\
\text { inlet holes } \\
(\boldsymbol{\Phi} \mathbf{1 0 m m})\end{array}$ & $\begin{array}{c}\text { No. of secondary } \\
\text { inlet holes } \\
(\boldsymbol{\Phi} \text { 30mm) }\end{array}$ & $\begin{array}{c}\text { No. of holes in the combustion } \\
\text { cylinder }(\boldsymbol{\Phi} \mathbf{5 m m}) \\
\text { (holes in one row } \times \text { no. of rows) }\end{array}$ \\
\hline M1 & None & 28 & 2 & $26 \times 26$ \\
\hline M2 & None & 28 & 2 & $26 \times 3$ \\
\hline M3 & Angled & 28 & 2 & $26 \times 3$ \\
\hline M4 & Angled & 28 & 4 & $40 \times 3$ \\
\hline M5 & Angled & 28 & 4 & $40 \times 3$ \\
\hline M6 & Curved & 28 & 4 & $40 \times 3$ \\
\hline M7 & Curved & 11 & 4 & \\
\hline
\end{tabular}

perspectives. Power output, which is based on the amount of gas produced in a unit time, is a factor that mainly depends on the temperature in the fuel container, the availability of the primary and secondary airflow, the diameter and height of the combustion chamber and the type of fuel used. The burn rate is speeded up if the primary air flow is high. Therefore, maintaining the primary airflow at a moderated speed is immensely necessary work. At the same time, the secondary airflow has to be high to combust with the producer gas, or else unburnt gases will emit into the atmosphere.

Air can be circulated naturally and also using a fan or blower, where it is called forced air or fan assisted. When the fuel and air supply to the stove is kept constant, the heat output rate of the stove depends on the area of the combustion container. If high power is needed, the cross-sectional area of the container should be high. Also, the height of the combustion container is a parameter that determines the quantity of syngas and the biomass combustion time [22].

This domestic TLUD cookstove is designed while considering the above-mentioned design perspectives. The user's perspectives like easy handling, inserting raw materials, removing biochar and ash were considered. Also, the power output of the cookstove should be capable to cook for an average of four people at one burning process.

\subsubsection{Dimensional Analysis}

When designing the TLUD cookstove with novel features, mainly the volume of the combustion cylinder and the primary and secondary airflow are taken into consideration. As the fuelwood of the designed stove, corn cobs or cinnamon stick chips which are widely found in SriLanka are used, they provide a clearer path for the airflow through the cavities among them.

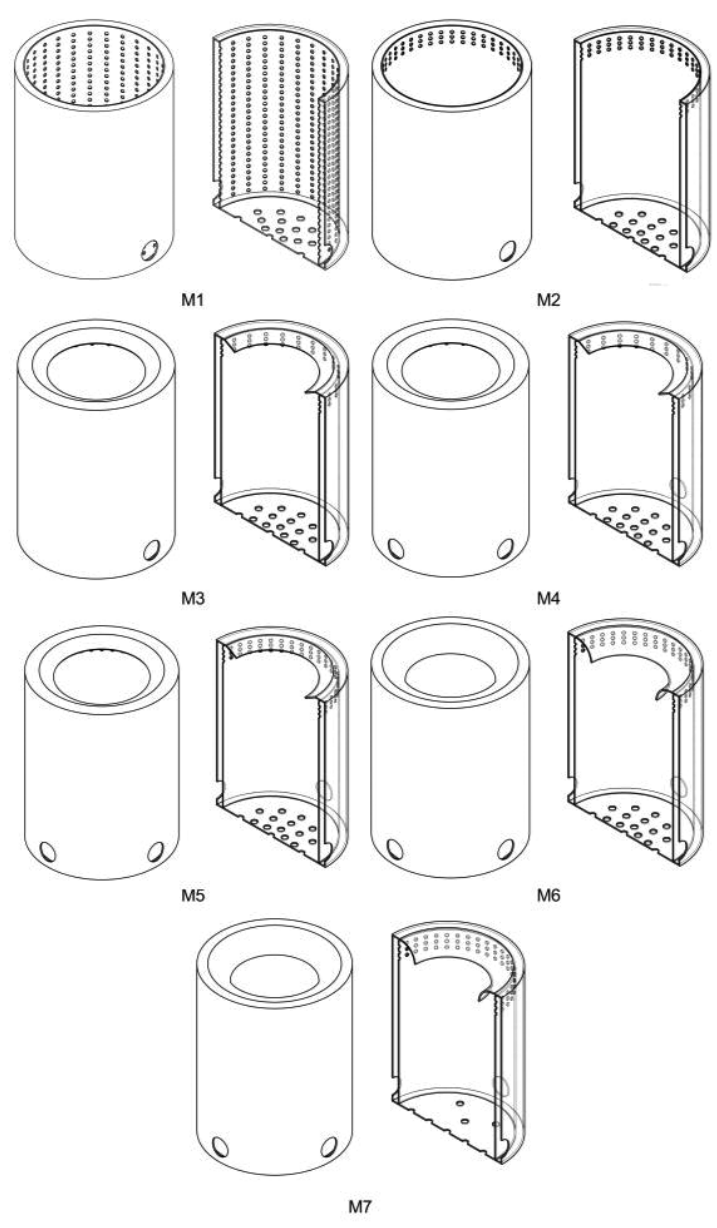

Figure 1 - Isometric and Section Views of the Cookstove Designs used in Simulation

The power output $(Q)$ from a cookstove can be expressed as a function of low heating value (LHV) or the calorific value of the fuel and fuel consumption rate $\left(\dot{m}_{b m s}\right)$. The biomass consumption rate can be calculated using Equation ...(1) with an expected efficiency $(E)$ in a range of $35-45 \%$. It is estimated that the amount of energy needed to cook for a family of four members is $5 \mathrm{MJ} / \mathrm{s}$. The calorific value of corn cobs is taken as $17.4 \mathrm{MJ} / \mathrm{kg}$ [23].

$$
\dot{m}_{b m s}=\frac{Q}{E * L H V}
$$


The diameter of the combustion chamber $(D)$ is calculated using Equation ...(3) with the relation for the specific biomass consumption $\left(\dot{\mathrm{m}}^{\prime}{ }_{\text {bms }}\right)$ taken as $0.025 \mathrm{~kg} / \mathrm{m}^{2} \mathrm{~s}$ from the experimental results conducted with the existing biomass cookstove.

$$
\begin{gathered}
\dot{m}_{b m s}^{\prime}=\frac{\dot{m}_{b m s}}{\text { Area of the }} \\
D=\sqrt{\frac{4 * \dot{m}_{b m s}}{p i * \dot{m}_{b m s}^{\prime}}}
\end{gathered}
$$

The height of the combustion chamber is calculated using Equation ...(4) which depends on the specific biomass consumption rate $\left(\dot{m}_{b m s}^{\prime}\right)$, biomass bulk density (den $\left.n_{b m s}\right)$ and cooking time $(t)$. Corn cobs have a density of $282.38 \mathrm{~kg} / \mathrm{m}^{3}$ [24] and it is expected to have a cooking time of 50 minutes for the new cookstove design. Using the equations, the diameter of the combustion chamber is calculated as $190 \mathrm{~mm}$ and height as $265 \mathrm{~mm}$.

$$
h=\frac{\dot{m}_{b m s}^{\prime} * t}{d e n_{b m s}}
$$

The thermal performance and the emissions are key performance parameters in a biomass cookstove which mostly rely on the airflow rates of primary and secondary supply pattern and the location of air inlets. Therefore, it is important to analyse and identify the correct flow pattern in the cookstove to achieve optimum performance. Primary air assists in producing the pyrolysis gas in natural draft TLUD stoves and at the top of the stove pyrolysis gas is ignited by the secondary air. Depending upon the secondary air flow rate the pyrolysis gas can be removed unburnt or, if there is a surplus in the secondary air supply, pyrolysis gas can be cooled down. Therefore, it is necessary to consider primary and secondary airflow inside the cookstove as design considerations.

Different design configurations and their geometrical details are shown in Figure 1 and Table 1 which are used for the simulation purpose. The dimensions of the cookstove design developed by Rodrigo et al. [21] was altered based on the dimensional analysis while retaining the primary and secondary hole pattern and developed the M1 design configuration. Modifications were made considering the top end geometry, no. of primary and secondary holes and hole patterns in the combustion cylinder, no. of secondary air inlet holes in the outer cylinder and the relative location to develop the design configurations M2, M3, M4, M5, M6 and M7.

\subsection{Basic Governing Equations for Analyzing the Cookstove}

To analyse the airflow and temperature distribution inside the combustion chamber, CFD techniques were used which are incorporated with ANSYS FLUENT. It is important to select the suitable equations which are to be solved for the simulation. Threedimensional governing equations are solved to obtain the fluid properties such as velocity, temperature, pressure and density based on boundary conditions and flow assumptions.

As the airflow inside the combustion chamber is turbulent to solve the unknown terms, a suitable turbulent model should be defined. The $k$-epsilon $(k-\varepsilon)$ turbulent model was selected where it is used in most engineering applications with greater accuracy. The two terms $k$ and $\varepsilon$ are identified as turbulent kinetic energy and dissipation rate, respectively [25].

\subsection{Simulation Model}

ANSYS Fluent version 16.0 was used for the simulation. The simulation model which was developed for the existing biomass cookstove was applied for the different design configurations to obtain the temperature and velocity distributions. In the model, the biochar at the combustion state was replaced with a cylindrical volume. The average temperature value of $\mathrm{T}=1329 \mathrm{~K}$ was assigned for this cylindrical volume. The temperature value was based on the results of the experiments performed using the existing cookstove. The unstructured tetrahedral mesh was used which can be simulated with the available resources in the laboratory (Intel Xeon processor E3-1240, 32 GB, 3.3 GHz). The gaseous phase was modelled while assuming it to be incompressible and transient flow. The flow inside the combustion chamber is normally turbulent and as the viscous turbulent model, the realizable $k$ $\varepsilon$ turbulent model was used with standard wall functions.

Table 2 - Boundary Conditions and the Cell Zone Values

\begin{tabular}{ll}
\hline Parameters & Value \\
\hline Inlet air temperature $(\mathrm{K})$ & 303.15 \\
\hline Inlet gauge pressure $(\mathrm{Pa})$ & 0 \\
\hline $\begin{array}{l}\text { The temperature of the } \\
\text { biomass volume }(\mathrm{K})\end{array}$ & 1329 \\
\hline Outlet gauge pressure $(\mathrm{Pa})$ & 0 \\
\hline
\end{tabular}

The boundary conditions used in the simulation are shown in Table 2. The inlets (primary and secondary) and outlet of the model were 
selected as pressure inlet and outlet with zero pascal gauge pressure. A constant inlet air temperature was assigned which is equal to the average ambient air temperature around the experimental area. The flow occurs inside the combustion chamber due to natural convection. Therefore, for the air properties, incompressible ideal gas was selected for the density variation because the density should be varied with the temperature to occur natural convection.

\subsection{Experimental Apparatus}

The design consists of three cylindrical chambers: outer cylinder, inner cylinder and combustion cylinder. Stainless steel plates (gauge 18) were used to fabricate these three cylindrical chambers. The height and diameter of the combustion chamber were selected according to the dimensional analysis done in section 2.1.1. To minimize the heat transfer to the surrounding, insulation was done by inserting glass wool to space in between outer and inner cylinders. All three cylinders were fabricated to have a common axis.

The design consists of four secondary air inlet holes at $90^{\circ}$ to each hole in the outer cylinder and inner cylinder with a diameter of $30 \mathrm{~mm}$. Secondary air passes through these holes in the two cylinders to reach the combustion chamber. It was designed to have secondary outlet holes of diameter $5 \mathrm{~mm}$. The hole pattern in the combustion chamber is designed to have a better mixing of air for the combustion with pyrolysis gas. The primary air inlet was placed at the bottom of the cookstove with a hole diameter of $10 \mathrm{~mm}$ along with a manual air controller. This can be used to control the primary airflow rate.

Experiments were performed using the best design selected after analysing the simulation results. During the combustion, the temperature of the raw materials and air inside the stove were measured using the Rex-C900 temperature controller at five places along with the height of the combustion cylinder. Corn cobs were used as the biomass fuel and the temperature measurements were taken at the hot start phase.

\section{Results and Discussion}

The simulation results for the temperature, density and air distribution velocity are shown in Figure 2, Figure 3 and Figure 4, respectively. These simulation results turn out to be advantageous when they are much closer to the experimental results. With the aid of accurate

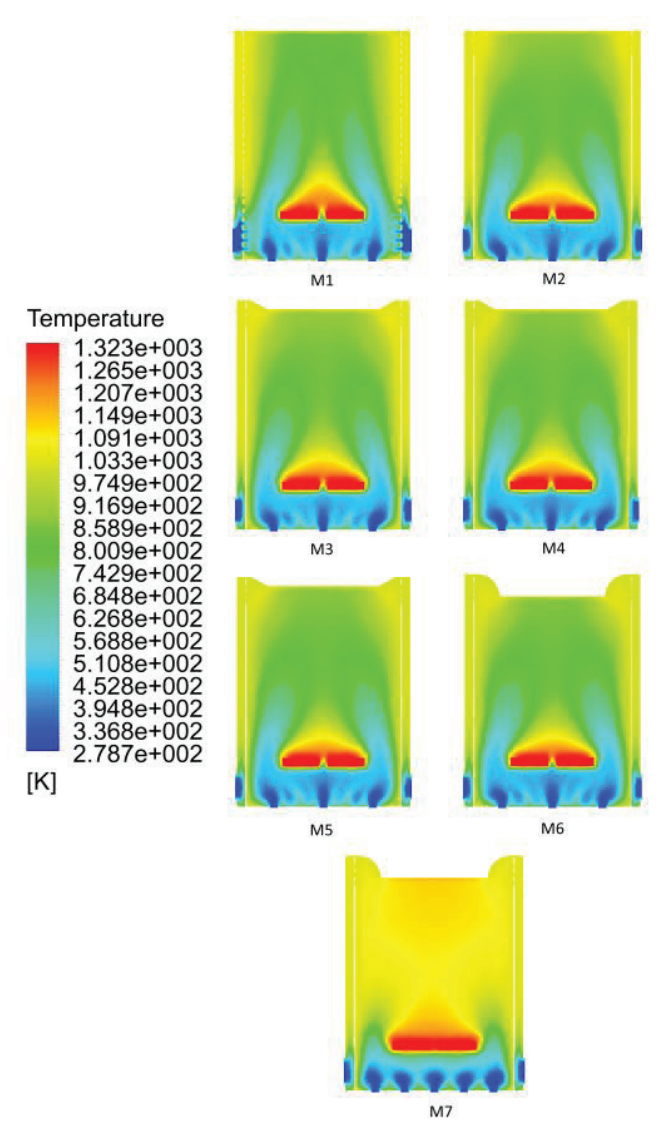

Figure 2 - Temperature Distribution on the Midplane of Seven Design Configurations

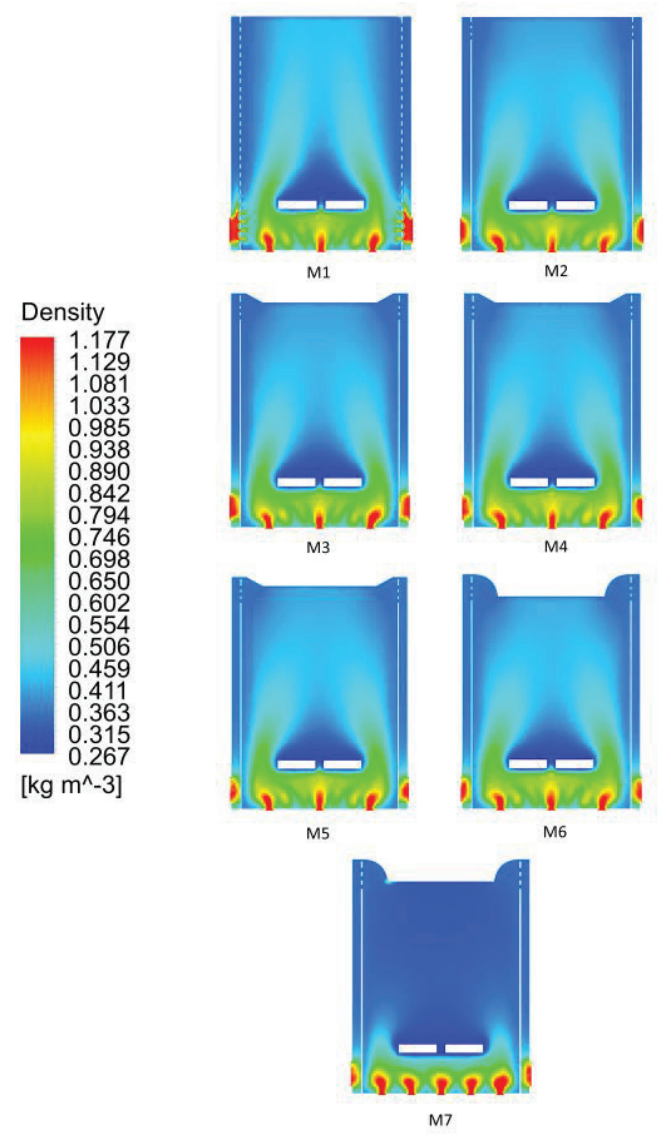

Figure 3 - Density Distribution on the Mid Plane of Seven Design Configurations 

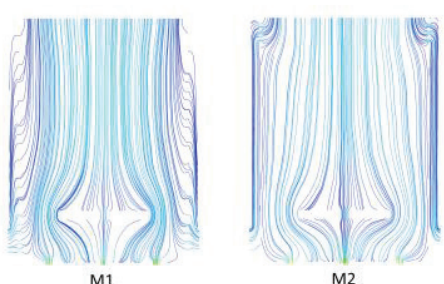

$\mathrm{M}$

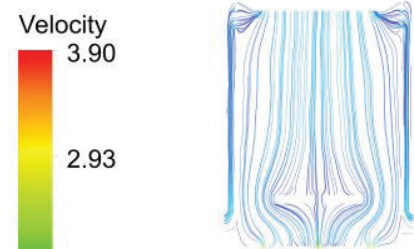

M3

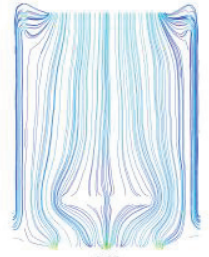

M4

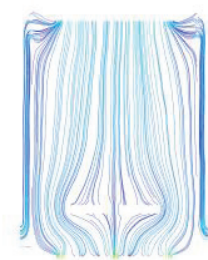

M5

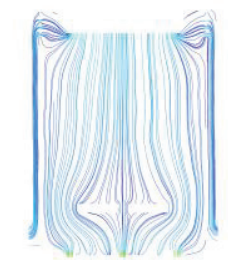

M6

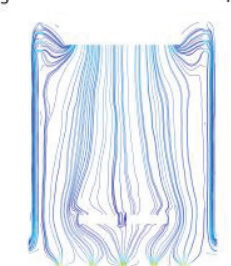

M7

Figure 4 - Velocity Path Lines on the Midplane of the Seven Design Configurations

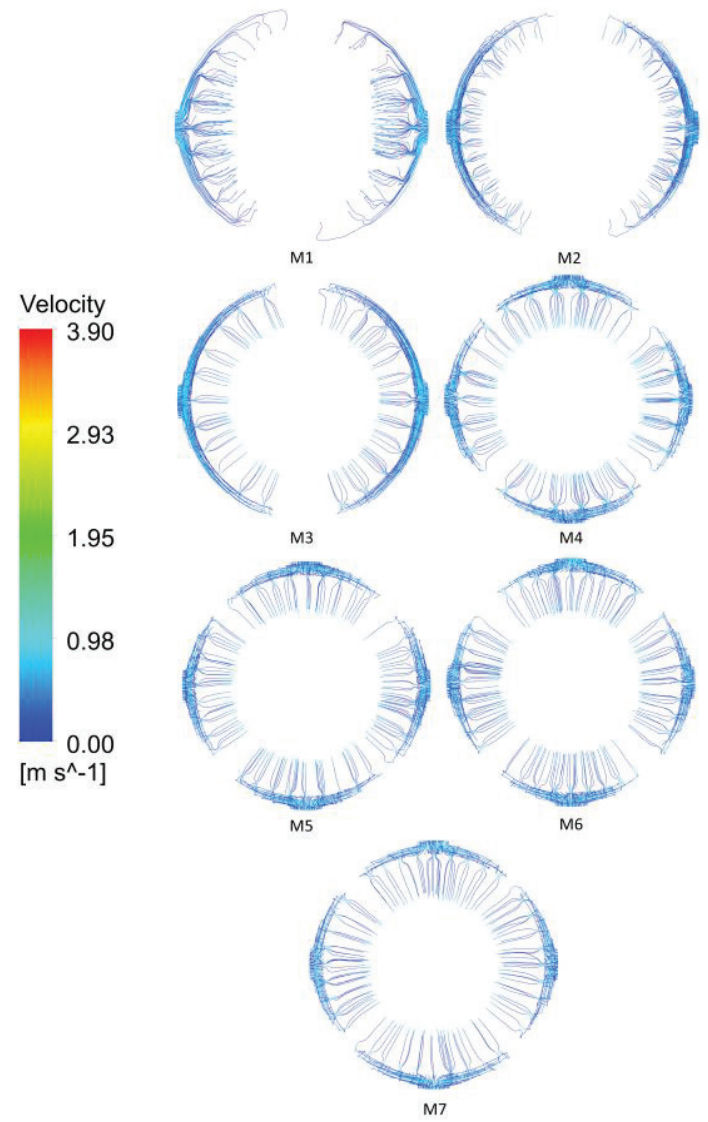

Figure 5 - Top View Velocity Path Lines of Seven Design Configurations
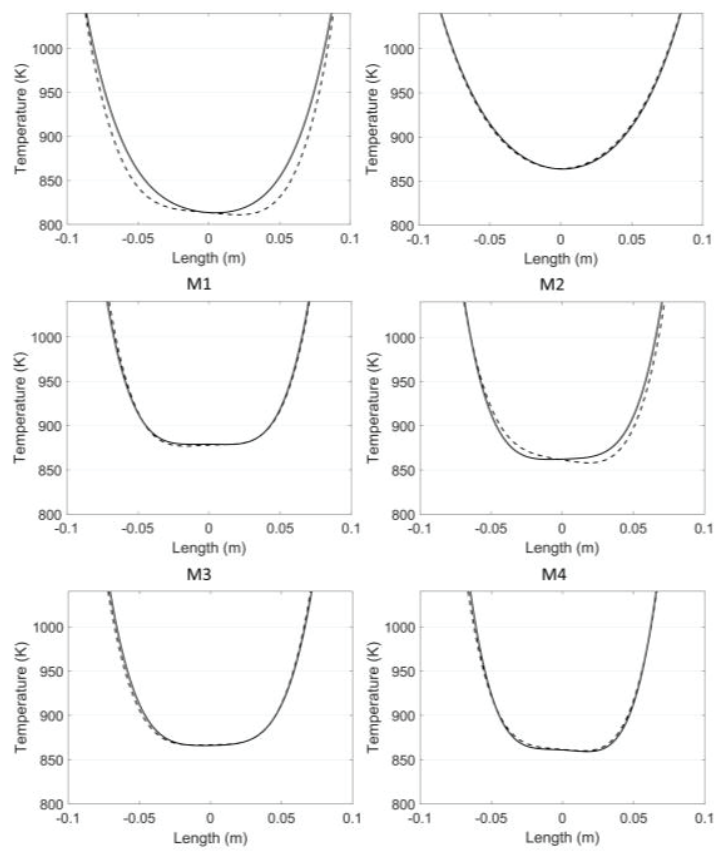

M5 M6

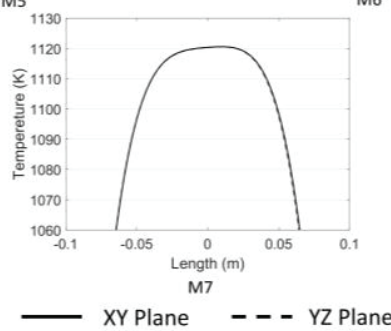

Figure 6 - Temperature Variation in the Combustion Chamber near the Outlet of Each Design in the XY Plane and YZ Plane

validation, cookstove performance and physical properties like temperature, density, pressure and air distribution can be predicted.

Inlet air temperature is at ambient temperature which reaches a maximum around the cylindrical volume used as a burning stage of biomass with a constant temperature. In this zone, the possibility for gasification and pyrolysis is increased due to the presence of higher temperature and low oxygen. At the outlet, the temperature value remains at a lower value relative to the temperature around the heat source. The density variation couples with the temperature variation, showing a higher density at the inlets and a lower density value at the outlet, as shown in Figure 3. Figure 6 shows the temperature variation near the air outlet of each design configuration in $X Y$ and $Y Z$ planes. Two temperature distribution values in $X Y$ and $Y Z$ planes showed a good correlation for each design model (correlation coefficient $\quad \mathrm{r} ; \quad \mathrm{M} 1=0.9929, \quad \mathrm{M} 2=0.9995$, M3 $=0.9974, M 4=0.9814, M 5=0.9952, M 6=0.9968$, $\mathrm{M7}=0.9971$ ). The temperature distribution is almost axisymmetric even though the no. of main secondary air inlets and hole pattern in the combustion chamber vary. The graph of the 


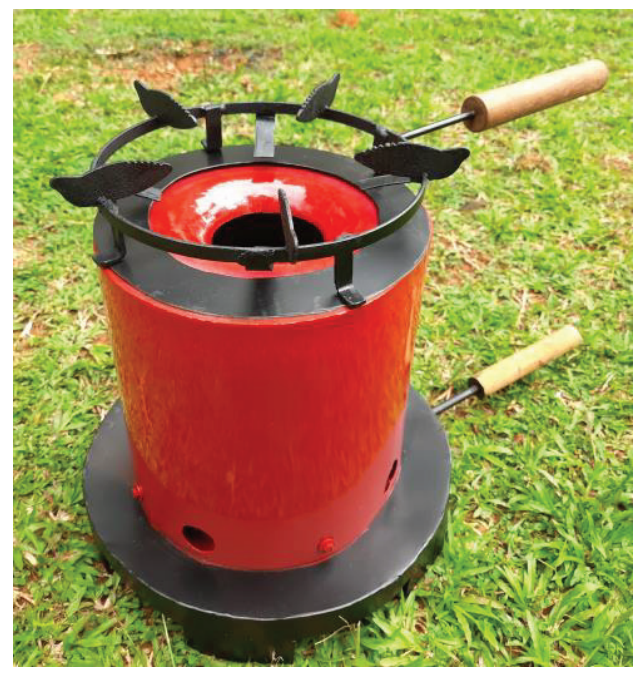

Figure 7 - Experimental Apparatus

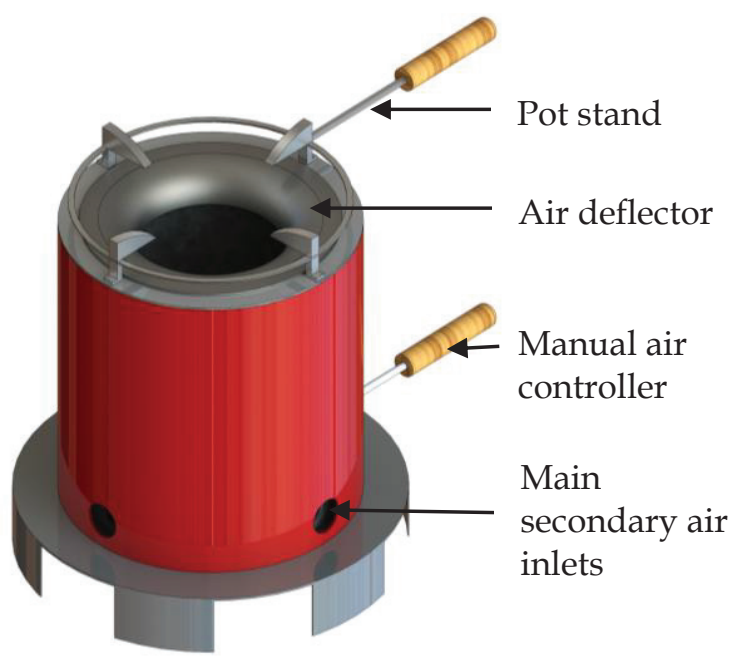

Figure 8 - 3D Model of Design M7

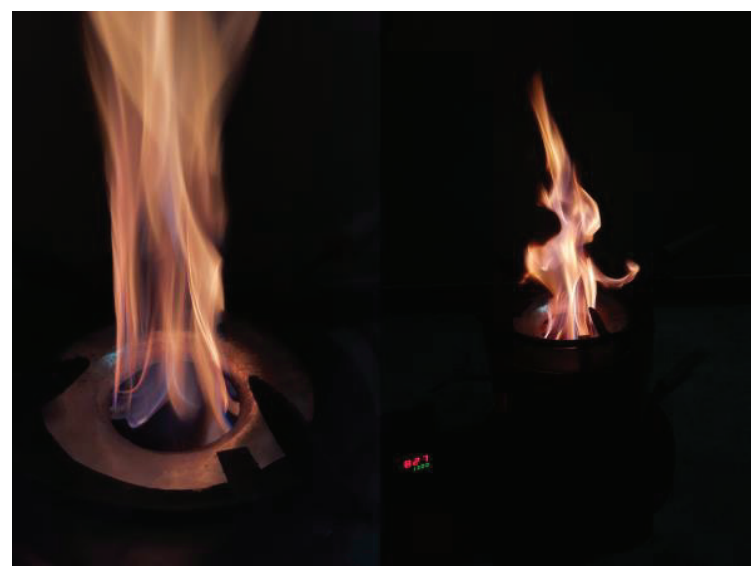

Figure 9 - Temperature Measurement using REX-C900 Temperature Probe

M7 shows a local maximum near the centre axis compared to other design configurations. It can be visualized from Figure 2 and Figure 6 that the temperature distribution is almost the same for M1, M2, M3, M4, M5 and M6 configurations. In the M7 configuration, the temperature distribution above the cylindrical volume used as a burning stage of biomass is high compared to other design configurations due to less primary air inlets.

Primary and secondary airflow is a result of the buoyancy force created due to the variation of air density. Higher temperature accounts for lower density and creates a convection current leaving the air inside the combustion chamber. This draws air at ambient temperature through the primary and secondary inlets.

Figure 4 shows the velocity path lines of inlet air (primary and secondary air) on the $\mathrm{XY}$ plane. M1 configuration provides a nonuniform distribution of secondary air for the combustion chamber throughout its height. This air distribution is inefficient when the fuel stack level is in the top and middle positions because secondary air doesn't mix properly with producer gas to occur combustion throughout the combustion process at the top of the fuel stack. And also, it supplies more oxygen to the pyrolyzing area resulting in a non-effective pyrolyzing process. In contrast, M2, M3, M4, M5, M6 and M7 configurations divert secondary air to the combustion chamber allowing it to mix with producer gas at the top of the fuel stack throughout the firing time of the cookstove by having only three inlet hole rows at the top of the combustion cylinder. Figure 5 shows the top view of the secondary air distribution of M1, M2, M3, M4, M5, M6 and M7 design configurations. In the M1 design configuration, the secondary air density near the main secondary inlets is much greater and poorly distributed around the combustion cylinder when compared with other designs. The M2, M3 and M4 configurations have 78 inlet holes (26 inlet holes in a row $\times 3$ rows) in the combustion cylinder while M5, M6 and M7 configurations have 120 inlet holes (40 inlet holes in a row $\times 3$ rows). The distribution of secondary air has become more uniform with the increase of inlet holes in the combustion cylinder. It can be visualized that having four main secondary inlets, the air is distributed all around the perimeter of the cookstove combustion cylinder in M4, M5, M6 and M7 designs than having two main secondary inlets. Better distribution of secondary air and uniform mixing with producer gas occurs with the higher number of inlet holes in the combustion cylinder.

The geometrical shape at the top of the cookstove design influenced more on the air distribution pattern than on the air temperature 


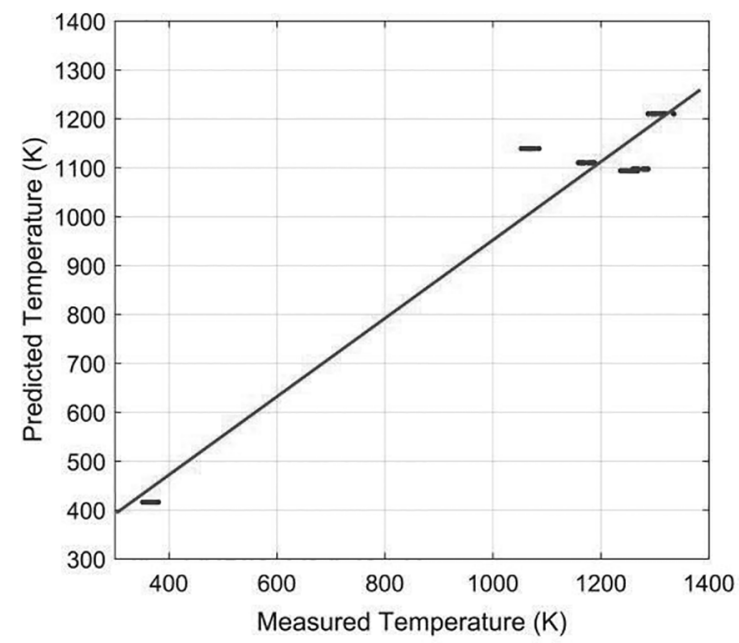

Figure 10 - Comparison of the Results of Experimental and CFD Predicted Temperature in the Combustion Chamber

distribution. Inlet air is not handled by any deflector in both M1 and M2 designs and the air is directed freely through the outlet. In the M2 design configuration, secondary air leaves the combustion chamber as soon as it enters. By introducing a deflector, the secondary air is allowed for proper mixing with the producer gas. Angled deflectors are introduced for the M3, M4 and M5 design configurations. M6 and M7 designs have curved deflectors which is good at diverting air with a uniform airflow and allows a better mixing with the producer gas.

\subsection{Comparison Between the Experimental and the CFD Analysis Data}

Examining the simulation results, the M6 design ensures a better distribution of primary and secondary air through primary and secondary air inlet holes into the combustion chamber. This provides significant importance for the efficient combustion of producer gas and the process of biomass gasification. But because it supplies more oxygen to the pyrolyzing zone, a non-efficient pyrolyzing process occurs, thus non-efficient production of biochar takes place.

The model of the selected M7 design is shown in Figure 8. Figures 7 and 9 show the experimental setup. The blue flame of the stove can be identified in Figure 9. Experiments were carried out having corn cobs as the raw material with the new biomass cookstove to validate the model designed and simulated in ANSYS Fluent to determine the heat transfer and the airflow inside the cookstove. The temperature values of ten experimental trials were compared with the corresponding CFD results obtained for the selected design, M7, and illustrated in Figure 10. The results showed a good correlation $(r=0.9667)$ and a higher $R^{2}$ (coefficient of determination) value.

\section{Conclusions}

CFD simulation for seven different geometrical designs was performed and the results were analysed to identify a design with better performance.

- It was concluded that uniform velocity distribution can be obtained by increasing the number of main secondary inlets in the outer cylinder and by increasing the number of holes around the combustion cylinder.

- Reducing the number of primary inlets caused increasing of the temperature of producer gas, which allows for better combustion and also permits to have an efficient pyrolyzing zone with less oxygen.

- Having deflectors increase the quality of the secondary air and producer gas mix, design M7 is selected as the best design with four main secondary inlets, 11 primary inlets and a curved deflector.

- However, using this design we were unable to obtain the full controlling capability of the output heat through the manual air controller and thus was identified as a suggestion to improve.

- This simulation model can be used for simulating and designing similar natural draft TLUD cookstoves of different fuel consumption rates, firing time and efficiencies.

- As future works, comprehensive modelling of biomass gasification and combustion processes can be performed to analyse the emissions. This could be useful for introducing an efficient biomass cookstove with lower emissions for household usage.

\section{References}

1. World Health Organization, "WHO Indoor Air Quality Guidelines: Household Fuel Combustion," 2014.

2. Lehmann, J., "Bio-Energy in the Black", Front. Ecol. Environ., Vol. 5, No. September, pp. 381$387,2007$.

3. World Health Organization, "Global Health Observatory and Repository", 2015. [Online]. Available: 
https:/ /apps.who.int/gho/data/view.main.170 1?lang=en. [Accessed: 05-Mar-2020].

4. Anderson, P. S., "TLUD Stoves in 2011: Within a Classification of Stoves", in ETHOS Conference, 2011, pp. 28-30.

5. Reddy, S. B. N., “Understanding Stoves for Environment and Humanity", 1st ed. MetaMeta, 2012.

6. Perera, K. K. C., and Sugathapala, A. G. T., "Fuelwood Fired Cookstoves in Sri Lanka and Related Issues", Energy Sustain. Dev., Vol. 6, No. 1, pp. 85-94, 2002.

7. Sohi, S. P., Krull, E., Lopez-Capel, E., and Bol, R., "Chapter 2 - A Review of Biochar and Its Use and Function in Soil", in Advances in Agronomy, Vol. 105, Academic Press, pp. 47-82, 2010.

8. Bhadha, J. H., Jennewein, S., Sanchez, J., and Lang, T. A., "Producing Biochar using a Custom Designed Top-lit Up-draft (TLUD) Gasifier", pp. 1-4, 2014.

9. David, D., “A Fine Resolution CFD Simulation Approach for Biomass Cook Stove", Colorado State University, Colorado, 2011.

10. Ravi, M. R., Kohli, S., and Ray, A., "Use of CFD Simulation as a Design Tool for Biomass Stoves", Energy Sustain. Dev., Vol. 6, No. 2, pp. 20-27, 2002.

11. Kalla, S., Marcoux, H., and De Champlain, A., "CFD Approach for Modeling High and Low Combustion in a Natural Draft Residential Wood Log Stove", Int. J. Heat Technol., Vol. 33, No. 1, pp. 33-38, 2015.

12. MacCarty, N., Still, D., and Ogle, D., "Fuel Use and Emissions Performance of Fifty Cooking Stoves in the Laboratory and Related Benchmarks of Performance", Energy Sustain. Dev., Vol. 14, No. 3, pp. 161-171, 2010.

13. Raman, P., Ram, N. K., and Gupta, R. "Development, Design and Performance Analysis of a Forced Draft Clean Combustion Cookstove Powered by a Thermoelectric Generator with Multi-Utility Options", Energy, Vol. 69, pp. 813-825, 2014.

14. Kumar, M., Kumar, S., and Tyagi, S. K. "Design, Development and Technological Advancement in the Biomass Cookstoves: A Review", Renew. Sustain. Energy Rev., Vol. 26, pp. 265-285, 2013.

15. Kirch, T., Birzer, C. H., Van Eyk, P. J., and Medwell, P. R., "Influence of Primary and Secondary Air Supply on Gaseous Emissions from a Small-Scale Staged Solid Biomass Fuel Combustor", Energy and Fuels, Vol. 32, No. 4, pp. 4212-4220, 2018.
16. Mehta, Y., and Richards, C., "Effect of Airflow Rate and Secondary Air Jets on the Operation of TLUD Gasifier Cookstove", Int. J. Sustain. Energy, Vol. 39, No. 3, pp. 207-217, 2020.

17. Mukunda, H. S., Dasappa, S., Paul, P. J., Rajan, N. K. S., Yagnaraman, M., Ravi Kumar, D., and Deogaonkar, M.," Gasifier Stoves - Science, Technology and Field Outreach", Curr. Sci., Vol. 98, No. 5, pp. 627-638, 2010.

18. Kshirsagar, M. P., and Kalamkar, V. R., "A Comprehensive Review on Biomass Cookstoves and a Systematic Approach for Modern Cookstove Design", Renew. Sustain. Energy Rev., Vol. 30, pp. 580-603, 2014.

19. Gunawardena, M. L., Dharmakeerthi, R. S., and Dassanayake, K. M. M., "A Green Technology to Generate Bio-Energy While Producing Biochar", Proceedings of the Energy Symposium SriLanka $2015,2^{\text {th }}$ and $27^{\text {th }}$ June, Hilton, Colombo.

20. Dassanayake, K. M. M., Perera, B. S. N., Fernando, W. D. S., and Dharmakeerthi, R. S., "Eco Friendly Energy and Biochar Producing Stove", in Proceedings of Annual session of IESL, , pp. 1-9, 2016.

21. Rodrigo, T. M. T. C., Rajamanthree, U. R. T. Y., Dassanayake, K. M. M., “Designing of a Stove to Produce Bio-Char and Bio-Energy in Small Scale", Proceedings of Annual Research Symposium (ARS) 2019, Faculty of Engineering, University of Ruhuna.

22. Roth, C., "Micro-gasification: Cooking with Gas from Biomass", GIZ Hera, p. 100, 2011.

23. Posom, J., and Nakawajana, N., "Gross Calorific Value Estimation for Milled Maize Cob Biomass using Near Infrared Spectroscopy", in The 4th International Conference on Engineering, Applied Sciences and Technology (ICEAST), Vol. 192, pp. 2-5, 2018.

24. Zhang, Y., Ghaly, A. E., and Li, B., "Physical Properties of Corn Residues", Am. J. Biochem. Biotechnol., Vol. 8, No. 2, pp. 44-53, 2012.

25. ANSYS Inc., Fluent 16.0 Theory Guide. 2015. 